\title{
MICROSCOPE IN DENTISTRY: A REVIEW ARTICLE
}

\author{
SUMAN MUKHERJEE ${ }^{1 *}$, SHARMISTHA DASGUPTA ${ }^{2}$
}

${ }^{1}$ Department of Periodontics and Oral Implantology, Arogya Bardini Polyclinic, Puruliya, West Bengal, India. ${ }^{2}$ Department of Periodontics and Oral Implantology, RHT Multispeciality Clinic, New Delhi, India. Email: smjee234@gmail.com

Received: 03 February 2021, Revised and Accepted: 24 February 2021

ABSTRACT

The microscope has been one of the oldest yet most exquisite inventions in human history. The lenses changed the future of medical science and its abstraction forever. Previously, humans never know much about the source of disease, but today we know that the universe of microbes is vaster and more limitless than it ever was. However, the microscope is not just limited to laboratory in vitro research and study; it has remodeled dentistry more today than ever. This article describes the various types of microscopes used in periodontics, endodontics, and oral pathology in dentistry.

Keywords: Microscope, Dark field, Electron, Viruses, Loupes, Microsurgery, Confocal, Compound, Microbes.

(C) 2021 The Authors. Published by Innovare Academic Sciences Pvt Ltd. This is an open access article under the CC BY license (http://creativecommons. org/licenses/by/4.0/) DOI: http://dx.doi.org/10.22159/ijms.2021v9i2.41044. Journal homepage: https://innovareacademics.in/journals/index.php/ijms

\section{INTRODUCTION}

The microscope has been one of the oldest yet most exquisite inventions in human history [1]. The lenses changed the future of medical science and its abstraction forever. Previously, humans never know much about the source of disease, but today we know that the universe of microbes is vaster and more limitless than it ever was. However, the microscope is not just limited to laboratory in vitro research and study; it has remodeled dentistry more today than ever. In periodontics, surgical microscopes and loupes have been playing a key role in microsurgery. Since, its advent in root coverage procedures and flap procedures, surgical loupes are gaining attention and interest. As such, we need to know the past of this novel discovery which changed the beliefs of medicine in general, and dental science in particular forever [2-4].

\section{TIMELINE OF THE MICROSCOPE}

- $\quad 1^{\text {st }}$ century AD (year 100) - Romans invented Glass [5]

- 1300 A.D. - Concave and Convex lenses first came into general use for spectacles [6]

- Robert Bacon (1212-1294) - believed to be the first person to combine to lenses $[6,7]$

- $14^{\text {th }} \mathrm{AD}$ spectacles first made in Italy $[8,9]$

- 1590 - Two Dutch spectacle-makers and father-and-son team, Hans and Zacharias Janssen, create the first compound microscope [10-13]

- 1666 - Italian scientist Marcello Malpighi, called the father of histology by some historians of biology, began his analysis of biological structures with the lungs [14-16]

- 1667: Robert Hooke's famous "Micrographia" is published, which outlines Hooke's various studies using the microscope [17-20]

- 1675: Anton van Leeuwenhoek, who used a microscope with one lens to observe insects and other specimens. Leeuwenhoek was the first to observe bacteria $[21,22]$

- $18^{\text {th }}$ century: As technology improved, microscopy became more popular among scientists. Part of this was due to the discovery that combining two types of glass reduced the chromatic effect [23]

- 1830: Joseph Jackson Lister discovers that using weak lenses together at various distances provided clear magnification [23-25]

- 1873: Ernst Leitz microscope was introduced with a revolving mount (turret) for five objectives [26,27]

- 1878: A mathematical theory linking resolution to light wavelength is invented by Ernst Abbe [28-31]

- 1878: Oil immersion lens (cedar oil) were introduced that resulted in a homogeneous optical path [32]
- 1903 - Richard Zsigmondy won Nobel prize for his phase-contrast microscope

- 1904: The first commercial ultraviolet (UV) microscope by Zeiss [33-36]

- 1930: Fritz Zernike discovered that he could view unstained cells using the phase angle of rays. It took until 1941 to bring a commercial microscope to market

- 1931: Ernst Ruska co-invented an electron microscope for which he won the Nobel Prize in Physics in 1986

- 1937: First scanning electron microscope was built [37]

- 1939 - Siemens supplied the first commercially available electron microscope [38,39]

- 1953: Zernike was awarded the Nobel Prize for his phase-contrast work [40]

- 1981: Gerd Binnig and Heinrich Rohrer invented a scanning tunneling microscope that gives three-dimensional images of objects down to the atomic level. Binnig and Rohrer won the Nobel Prize in Physics in 1986 [41,42]

- 1982 - A scanning the probe microscope was invented that works by measuring current

- 1983 - Scanning laser confocal microscope was commercially available [43-45]

- 1986 - The atomic force microscope (AFM) was invented that measures force instead of current [46-48]

- 1986 - Gerard Bining Heinrich Rohrer Discovered atomic microscope in 1981 and won Nobel prize for it in 1986

- Cryo-electron microscopy innovators win 2017 Nobel Prize in Chemistry.

The word "Microscope" is derived from the Ancient Greek word:

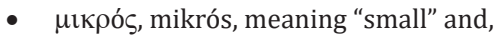

- бколعĩv, skopeîn, meaning "to look" or "see".

It was Giovanni Faber who coined the term microscope for the compound microscope Galileo submitted to the Accademia deiLincei in 1625 (Galileo had called it the "occhiolino" or "little eye").

A microscope can be defined as an instrument used to see objects that are too small for the naked eye. The science of investigating small objects using such an instrument is called microscopy. Microscopic means invisible to the eye unless aided by a microscope.

The ability to distinguish detail is called resolution or resolving power, and depends on the wavelength of light used and, on a value, called the 
numerical aperture a characteristic of microscopes that determines how much light enters the lens.

The limit of resolution of an objective (d) is the distance between any two closest points on the microscopic object, which can be resolved into two separate and distinct points on the enlarged image.

Limit of resolution $=d=\lambda / 2$ N.A.

\section{MAGNIFICATION POWER}

The magnification power measures how much larger an object appears after magnification. It is calculated by dividing the focal length of the scanning object (lens) by the focal length of the eyepiece.

A $\times 1$ magnification power is a $100 \%$ increase in the magnified object's size, for example, a 1 -inch object at $\times 1$ would appear to be 2 inches. At $\times 2$ power, the same object would appear to be 3 inches. Magnification power is reported on scientific reports as a means of standardization.

There are three well-known branches of microscopy: (Tables 1 and 2)

- Optical

- Electron

- Scanning probe microscopy.

\section{Optical microscope}

Optical microscopy is a technique employed to closely view a sample through the magnification of a lens with visible light. This is the traditional form of microscopy, which was first invented before the $18^{\text {th }}$ century and is still in use today [49].

\section{Binocular stereoscopic microscope}

It uses a magnification in the range of $\times 10-\times 100$. It allows easy observation of $3 \mathrm{D}$ objects at low magnification [50].

\section{Polarizing microscope/petrographic microscope}

It has a magnification range of $\times 4-\times 100$. It uses different light transmission characteristics of materials, such as crystalline structures, to produce an image. Materials that can be examined under a polarized microscope include minerals, ceramics, polymers, urea, and funguses. It is also used to study the property of collagen and amyloid [51-54].

\section{Differential interference contrast microscope}

It uses a magnification in the range of $\times 400-\times 1500$. This microscope, similar to the phase contrast, is used to observe minute surface irregularities but at a higher resolution. However, the use of polarized light limits the variety of observable specimen containers [55-58].

Table 1: In addition to the above categories, optical microscopes can be classified as follows

\begin{tabular}{ll}
\hline Biological & $\begin{array}{l}\text { With magnification ranging from } \times 50 \\
\text { to } \times 1500, \text { this microscope uses sliced } \\
\text { samples that are fixed onto slides for } \\
\text { observation } \\
\text { The binocular system allows } 3 \mathrm{D} \text { observation } \\
\text { of samples, such as insects or minerals, in } \\
\text { their natural state without the need to be } \\
\text { stereoscopic }\end{array}$ \\
microscope & to $\times 50$ \\
&
\end{tabular}

Table 2: Classification by structure

\begin{tabular}{ll}
\hline Upright microscope & $\begin{array}{l}\text { Observes targets from above. This type of } \\
\text { microscope is used to observe specimens } \\
\text { on slides }\end{array}$ \\
Observes targets from below. This \\
microscope is used to observe, for \\
example, cells soaked with culture in a \\
dish
\end{tabular}

Total internal reflection fluorescence microscope

It uses an evanescent wave to only illuminate near the surface of a specimen. The region that is viewed is generally very thin compared to conventional microscopes. Observation is possible in molecular units due to reduced background light [59-63].

\section{Multiphoton excitation microscope}

It uses multiple excitation lasers that reduce damage to cells and allows high-resolution observation of deep areas. It is used to observe nerve cells and blood flow in the brain [64-67].

\section{Structured illumination microscope}

It is a high-resolution microscope with advanced technology to overcome limited resolution found in optical microscopes that are caused by the diffraction of light [68-76].

\section{Scanning probe microscope/AFM}

It has a magnification of $\times 1,000,000$. In 1986, Binnig and Quate demonstrated for the $1^{\text {st }}$ time the ideas of AFM, which used an ultra-small probe tip at the end of a cantilever. This microscope scans the surface of samples with a probe and this interaction is used to measure fine surface shapes or properties. The optical and electron microscopes can easily generate two-dimensional images of a sample surface; However, these microscopes cannot measure the vertical dimension (z-direction) of the sample, the height (e.g., particles), or depth (e.g., holes, pits) of the surface features. 111-113 AFM, which uses a sharp tip to probe the surface features by raster scanning, can image the surface topography with extremely high magnifications, up to $\times 1,000,000$, comparable or even better than electronic microscopes. The measurement of an AFM is made in three dimensions, the horizontal X-Y plane, and the vertical $\mathrm{Z}$ dimension. Resolution (magnification) at Z-direction is normally higher than X-Y [77-84].

\section{Scanning near-field optical microscope (SNOM)}

NSOM/SNOM is a microscopic technique used for nanostructure investigation that breaks the far-field resolution limit by exploiting the properties of evanescent waves.

It is ideally suited to quickly and effortlessly image the optical properties of a sample with a resolution below the diffraction limit applied in nanotechnology research, nano-photonics, and nano-optics. In life science and materials research it is used for optical detection of the most minuscule surface. With SNOM, single-molecule detection is easily achievable. Dynamic properties can also be studied at a sub-wavelength scale. It provides a 70 times better resolution than an AFM [85-99].

\section{The compound microscope}

The word compound means multiple, mix, or a combination of both. A compound light microscope is a microscope with more than one lens and its light source. Because it contains its light source in its base, a compound light microscope is also considered a bright field microscope [100].

\section{Parts of a compound microscope}

- Mechanical parts - support and adjustment

- Magnifying parts - for enlargement of the specimen

- Illuminating parts - to provide light.

\section{WHAT CAN BE VIEWED}

Using stained prepared slides, you should see bacteria, chromosomes, organelles, protist or metazoans, smears, blood, negative stained bacteria, and thick tissue sections.

Utilizing unstained wet mounts for living preparations should enable you to see pond water, living protists or metazoans, and plant cells such as algae.

\section{USES/BENEFITS}

It can be used for blood analysis which is of great use in pathology labs to identify diseases. In forensic laboratories, it can be used to detect the 
presence or absence of minerals or metals at a crime scene, thereby aid in the criminal investigation.

\section{The phase-contrast microscope}

The phase-contrast microscope can show components in a cell or bacteria, which would be very difficult to see in an ordinary light microscope. Frits Zernike (1888-1966) received a Nobel prize in 1953 for his discovery of phase contrast [101-105].

\section{Altering the light waves}

The phase-contrast microscope uses the fact that the light passing through a transparent part of the specimen travels slower and, due to this is shifted compared to the uninfluenced light. This phase difference is not visible to the human eye. However, the phase change can be increased to half a wavelength by a transparent phase-plate in the microscope and thereby causing a difference in brightness. This makes the transparent object shine out in contrast to its surroundings.

\section{“INVISIBLE CAN BE SEEN"}

Transparent cells can be observed without staining them because the phase contrast can be converted into brightness differences. After all, it is not necessary to stain cells, cell division, and other processes can be observed in a living state.

\section{Applications}

- The sharp contrast in certain cases can only be seen through a phasecontrast microscope

- The high-contrast images of transparent specimens, such as microorganisms, thin tissue slices, living cells in culture, latex dispersions, lithographic patterns, glass fragments, and sub-cellular particles, such as nuclei and organelles, can be viewed in detail.

\section{Darkfield microscope}

This technique is used to observe unstained samples causing them to appear brightly lit against a dark, almost purely black, background. When light hits an object, rays are scattered in all azimuths or directions. The design of the dark field microscope is such that it removes the dispersed light, or zeroth order so that only the scattered beams hit the sample.

The introduction of a condenser and/or stop below the stage ensures that these light rays will hit the specimen at different angles, rather than as a direct light source above/below the object. The result is a "cone of light" where rays are diffracted, reflected, and/or refracted off the object, ultimately, allowing you to view a specimen in a dark field [106-114].

\section{Advantages of dark-field microscopy}

- It is used unstained slides, is transparent, and absorbs little or no light

- The specimens often have similar refractive indices as their surroundings, making them hard to distinguish with other illumination techniques

- It is used to study marine organisms such as algae and plankton, diatoms, insects, fibers, hairs, yeast, and protozoa as well as some minerals and crystals, thin polymers, and some ceramics

- It is used in the research of live bacterium, as well as mounted cells and tissues

- It is useful in examining external details, such as outlines, edges, grain boundaries, and surface defects than internal structure.

Darkfield microscopy is often dismissed for more modern observation techniques such as phase contrast and DIC, which provide more accurate, higher contrasted images and can be used to observe a greater number of specimens. But recently, the dark field has regained some of its popularity when combined with other illumination techniques, such as fluorescence, which widens its possible use in certain fields.

\section{Disadvantages}

The darkfield microscopy images are prone to degradation, distortion, and inaccuracies. A specimen that is not thin enough or its density differs across the slide, may appear to have artifacts throughout the image. The preparation and quality of the slides can grossly affect the contrast and accuracy of a dark field image. One needs to take special care that the slide, stage, nose, and light source are free from small particles such as dust, as these will appear as part of the image. We have to use oil or water on the condenser and/or slide, it is almost impossible to avoid all air bubbles. These liquid bubbles will cause image degradation, flare, and distortion and even decrease the contrast and details of the specimen.

\section{FLUORESCENT MICROSCOPE}

It uses a magnification of range $\times 1500$. On October 8,2014 , the Nobel Prize in Chemistry was awarded to Eric Betzig, William Moerner, and Stefan Hell for "the development of super-resolved fluorescence microscopy," which brings optical microscopy into the nano dimensions. It was British scientist Sir George G. Stokes who first described fluorescence in 1852.

In fluorescence microscopy, the sample you want to study is itself the light source. The technique is used to study specimens, which can be made to fluoresce.

The fluorescence microscope is based on the phenomenon that certain material emits energy detectable as visible light when irradiated with the light of a specific wavelength. A fluorescence microscope uses a much higher intensity light source which excites a fluorescent species in a sample of interest. This fluorescent species in turn emits a lower energy light of a longer wavelength that produces the magnified image instead of the original light source [115-119].

\section{Applications}

These microscopes are often used for:

- Imaging structural components of small specimens, such as cells

- Conducting viability studies on cell populations (are they alive or dead?)

- Imaging the genetic material within a cell (DNA and RNA)

- Viewing specific cells within a larger population with techniques such as FISH [120].

\section{CONFOCAL MICROSCOPE}

Confocal microscopy is a specialized form of standard fluorescence microscopy (also called wide-field fluorescence microscopy) that uses particular optical components to generate high-resolution images of material stained with fluorescent probes. It is rapidly gaining acceptance as an important technology because of its capability to produce images free of out-of-focus information. It provides a significant improvement in lateral resolution and the capacity for direct, non-invasive serial optical sectioning of intact, and thick living specimens.

Confocal microscopy offers several advantages over conventional optical microscopy, including shallow depth of field, elimination of outof-focus glare, and the ability to collect serial optical sections from thick specimens.

In the biomedical sciences, a major application of confocal microscopy involves imaging either fixed or living cells and tissues that have usually been labeled with one or more fluorescent probes [121-126].

\section{Applications}

The broad range of applications available to laser scanning confocal microscopy includes a wide variety of studies in neuroanatomy and neurophysiology, as well as morphological studies of a wide spectrum of cells and tissues. Other applications include resonance energy transfer, stem cell research, photobleaching studies, lifetime imaging, multiphoton microscopy, total internal reflection, DNA hybridization, membrane and ion probes, bioluminescent proteins, and epitope tagging. 
Many of these powerful techniques are described in these reviews. CLSM is widely-used in numerous biological sciences disciplines, from cell biology and genetics to microbiology and developmental biology.

\section{Electron microscope}

An electron microscope is a type of microscope that uses electrons to illuminate a specimen and create an enlarged image. It can magnify specimens up to 2 million times, while the best light microscopes are limited to magnifications of 2000 times. The greater resolution and magnification of the electron microscope are due to the wavelength of an electron, its de Broglie wavelength, being much smaller than that of a light photon, electromagnetic radiation [127].

\section{Transmission electron microscope (TEM)}

The way the image is created is similar to how a shadow is created with visible light. When the electron beam is transmitted through the sample, not all the electrons make it out. Some electrons are absorbed or deflected as they try to pass through the sample. The areas where more electrons made it through create bright spots on the screen below, and the areas where fewer electrons came through create darker spots. This, in turn, creates a magnified, shadow-like, black and white image of the sample.

SEM images are created by electrons that bounce off or are ejected from the sample. Because of this, the SEM gets surface images of the sample, whereas the TEM gets images of the internal composition of the sample. The downside of this in a TEM is that the sample must be cut very thin for the electrons to pass through, making sample preparation much harder than that of a sample used in an SEM.

The main application of a TEM is to provide high magnification images of the internal structure of a sample. Being able to obtain an internal image of a sample opens new possibilities for what sort of information can be gathered from it.

A TEM operator can investigate the crystalline structure of an object, see the stress or internal fractures of a sample, or even view contamination within a sample through the use of diffraction patterns, to name just a few kinds of studies [128-133].

\section{Scanning electron microscope}

When an SEM fires, an electron at the sample you want to magnify several different signals can be given off as the electrons strike the sample. Among the various signals given off, three of the most important are backscattered electrons, secondary electrons, and X-rays. The backscattered electrons occur when the collision is elastic. The backscattered electrons are the electrons that were originally shot at the sample bouncing back off of it. Conversely, secondary electrons occur when the collision is inelastic. Unlike backscattered electrons, secondary electrons originate from the sample itself. They are electrons that have been jarred loose from inside the sample.

We use these two types of electrons to make an image of the sample by scanning a beam of the fired electrons across the whole sample, hence the "scanning" in the scanning electron microscope. As the electron beam is scanned across the sample, detectors inside the microscope pick up the signals given off by this interaction. The detectors then use these signals to create the magnified image of the sample. The secondary electrons produce the highest quality images with the greatest possible magnification in the SEM. The backscattered electrons produce a worse quality image but also give information about the sample's composition.

The STEM provides structural and chemical information of a specimen at atomic-scale resolution and complements conventional transmission electron microscopy techniques. Mass measurements can now be performed routinely on a wide range of molecular and supramolecular structures using elastically scattered electrons. The recent progress in the acquisition and analysis of electron energy-loss spectroscopy data indicates that the scanning TEM is an efficient tool for mapping the chemical composition of biological samples [134-136].

\section{Reflection electron microscope (REM)}

In REM, the reflected beam of elastically scattered electrons is detected. It is used for looking at the microstructure of magnetic domains [137-139].

\section{Disadvantages of electron microscopy}

- It is expensive to buy and maintain

- Dynamic rather than static

- The specimen is specially prepared by sometimes lengthy and difficult techniques to withstand the environment inside an electron microscope.

\section{Modern day microscopes}

In the present day, the modest utility of the microscope as a tool in dental treatment has played a colossal role in building its usefulness.

Apotheker and Jako first introduced a commercial operating microscope to dentistry in 1981. Shanelec and Tibbetts took a step forward to introduce it in periodontics. Microscope in periodontics includes most commonly loupes, digital, and surgical microscopes. Dinolite is one of the original innovations of the $21^{\text {st }}$ century, with a handy size of a fat pen that offers low power zoom capabilities with magnification up to $\times 500$.

With the digital microscope, a live image transmission to a Tv or computer can be done. Plain assimilation of a microscope and digital camera helped in advancement and revolutionizing microphotography.

The dental loupes are simple combinations of two or more lenses. It is available as simple, compound, and prism loupes. It helps to alleviate the eye strain by magnifying the image when you are working on tiny objects and you need precision in surgery. The approach and concepts of "Minimally Invasive Surgery" and "Microsurgery" are based on the utility of the microscope in surgery.

Dental microscopes, as a highly sophisticated structure of lenses, give magnification between $\times 4$ and $\times 24$.

The magnification recommended for periodontal surgery is between $\times 10$ and $\times 20$. The dental microscope provides an ergonomic working posture, optimal, coaxial lighting of the operation region, and quite freely selectable magnification levels.

During surgical intervention, the surgeon uses both hands to perform the treatment procedure. For this reason, a motor-driven magnification changer, operated by a foot pedal, seems to be more ergonomic.

Conversely, if the magnification needs frequent change, it can be accomplished faster with the manual changer. To visualize lingual or palatal sites that are difficult to access, the microscope must have sufficient maneuverability. Recent technical advancement has further enabled direct viewing of oral operation aspects.

\section{CONCLUSION}

It is safe to say that microscopes have played a central part in life sciences.

This has positively contributed to the enhancement of quality of life since a lot of discoveries directly contributed to the development of drugs and cures used in the treatment of diseases and conditions that were previously misunderstood or not well understood.

A cell is the single unit of life, and to understand and study it, a microscope is necessary. The discovery of cells and genes was major milestones in the medical sciences and was a great influence on the development of new effective cures and a reduction of mortality cases among populations. 


\section{AUTHORS CONTRIBUTION}

Dr. Suman Mukherjee has written the manuscript; Dr. Sharmistha Dasgupta collects the data, edited, and revised the manuscript.

\section{AUTHORS FUNDING}

Nil.

\section{CONFLICTS OF INTERESTS}

Nil.

\section{REFERENCES}

1. Clay RS, Court TH. The History of the Microscope: Compiled from Original Instruments and Documents, up to the Introduction of the Achromatic Microscope. London: Holland Press; 1975.

2. Mary B. History of the Microscope. Thought Co.;2021. Available from: http://www.thoughtco.com/history-of-the-microscope-1992146.

3. The British Museum. The Nimrud Lens/the Layard Lens. Collection Database. The British Museum; 2012.

4. David B. The invention of the microscope. BIOS 2004;75:78-84

5. Mark C. "Roman Glass". Ancient History Encyclopedia. Available from: https://www.ancient.eu/article/592. [Last accessed on 2013 Aug 05]

6. Ilardi V. Eyeglasses and concave lenses in fifteenth-century Florence and Milan: New documents. Renaiss Q 1976;29:341-60.

7. Edward R. The invention of eyeglasses. J Hist Med 1956;2:183-218.

8. The Invention of Spectacles; 2004. The College of Optometrists. Available from: http://www.college-optometrists.org/en/college/ museyeum/online_exhibitions/spectacles/invention.cfm.

9. Eyeglasses through the Ages; 2016. Available from: http://www. antiquespectacles.com/history/ages/through_the_ages.htm.

10. Ball CS. The early history of the compound microscope. Bios 1966;37:51-60.

11. Available from: https://www.smithsonianmag.com/science-nature/ scientists-finally-unravel-mysteries-sperm-180963578.

12. Available from: http://www.lensonleeuwenhoek.net/content/ leeuwenhoeks-microscopes.

13. Available from: http://www.cas.miamioh.edu/mbi-ws/microscopes/ fathers.html.

14. Pearce JM. Malpighi and the discovery of capillaries. Eur Neurol 2007;58:253-5.

15. Romero RR. Marcello Malpighi (1628-1694), founder of microanatomy. Int J Morphol 2011;29:399-402.

16. DiDio LJ. Marcello Malpighi: The father of microscopic anatomy. Ital J Anat Embryol 1995;100 Suppl 1:3-9

17. Britannica T. Editors of Encyclopaedia, Robert Hooke. Encyclopedia Britannica; 2021. Available from: https://www.britannica.com/ biography/robert-hooke.

18. Woodruff LL. Hooke's micrographia. Am Natural 1919;53:247-64.

19. West JB. Robert Hooke: Early respiratory physiologist, polymath, and mechanical genius. Physiology 2014;29:222-33.

20. Gest H. The discovery of microorganisms by Robert Hooke and Antoni Van Leeuwenhoek, fellows of the Royal Society. Notes Rec R Soc Lond 2004;58:187-201.

21. Available from: http://www.bbc.co.uk/history/historic_figures/van leeuwenhoek antonie.shtml.

22. Lane N. The unseen world: Reflections on Leeuwenhoek (1677) "concerning little animals". Philos Trans R Soc Lond B Biol Sci 2015;370:20140344.

23. Available from: https://www.educationalgames.nobelprize.org/ educational/physics/microscopes/timeline/index.html.

24. Available from: https://www.micro.magnet.fsu.edu/optics/timeline/ people/lister.html

25. Available from: https://www.sciencelearn.org.nz/resources/1692history-of-microscopy-timeline.

26. Lines L. Fall-Leitz simple magnifiers. J Microscope Hist Soc 2006;14:1-93

27. Grehn J. Leitz-Microscopes for 125 Years. Rockleigh, NJ: E. Leitz, Inc.; 1977. p. 07647.

28. Gray N. Knowing the limit. Nat Cell Biol 2009;11:S8.

29. Volkmann H. Ernst abbe and his work. Appl Opt 1966;5:1720-31.

30. Available from: https://www.micro.magnet.fsu.edu/optics/timeline/ people/abbe.html.

31. Wimmer W. Carl zeiss, ernst abbe, and advances in the light microscope. Microsc Today 2017;25:50-7.
32. History of Oil Immersion Lenses. Available from: https://www. smecc.org/history_of_oil_immersion_lenses.htm.

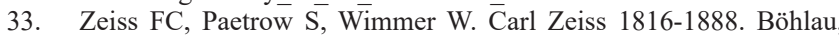
Weimar: A Biography; 2016.

34. Wimmer W. Carl Zeiss, Ernst abbe, and advances in the light microscope. Microscopy Today 2017;25:50-7.

35. Jena VB, Heidenheim CZ. Bibliographisches institut AG (Mannheim) v. VEB bibliographisches institut (Leipzig). Int Law Rep 1987;72:550-65.

36. Wollman AJ, Nudd R, Hedlund EG, Leake MC. From animaculum to single molecules: 300 years of the light microscope. Open Biol 2015;5:150019.

37. Shampo MA, Kyle RA. Ernst Ruska inventor of the electron microscope. Mayo Clin Proc 1997;72:148.

38. Big EJ. A short history of the electron microscope. Bios 1956;27:33-7.

39. "Scientists".; 2017. Available from: http://www.siemens.com/ global/en/home/company/about/history/people/scientists.html. [Last accessed on 2017 Oct 11]

40. NSF Awards Announced. Zernike awarded Nobel Prize. Phys Today 1953;6:28.

41. Binnig G, Rohrer H. Scanning tunneling microscopy. Surf Sci 1983;126:236-44

42. Binnig G, Rohrer H. Scanning tunneling microscopy. Helv Phys Acta 1982;55:726-35.

43. St. Croix CM, Shand SH, Watkins SC. Confocal microscopy: Comparisons, applications, and problems. Biotechniques 2005;39:S2-5.

44. Minsky M. Memoir on inventing the confocal scanning microscope. Scanning 1988;10:128-38.

45. White JG, Amos WB, Fordham M. An evaluation of confocal versus convential imaging of biological structures by fluorescence light microscopy. J Cell Biol 1987;105:41-8.

46. Binnig G, Quate CF, Gerber C. Atomic force microscope. Phys Rey Lett 1986;56:930-3.

47. Rugar D, Hansma P. Atomic force microscopy. Phys Today 1990;43:23-30.

48. Jaschke M, Butt HJ, Manne S, Gaub HE, Hasemann O, Krimphove F, et al. The atomic force microscope as a tool to study and manipulate local surface properties. Biosens Bioelectron 1996;11:601-12.

49. Agocs E, Attota RK. Enhancing optical microscopy illumination to enable quantitative imaging. Sci Rep 2018;8:4782.

50. Ki-Chul K, Young-Tae L, Nam K, Kwan-Hee Y, Hong JM, Park GC. High-definition 3D stereoscopic microscope display system for biomedical applications. EURASIP J Image Video Proc 2010;2010:724309.

51. Wang Z, Zheng W, Hsu SC, Huang Z. Optical diagnosis and characterization of dental caries with polarization-resolved hyperspectral stimulated Raman scattering microscopy. Biomed Opt Express 2016;7:1284-93.

52. Rajan R, Krishnan R, Bhaskaran B, Kumar SV. A polarized light microscopic study to comparatively evaluate four remineralizing agents on enamel viz CPP-ACPF, ReminPro, SHY-NM and colgate strong teeth. Int J Clin Pediatr Dent 2015;8:42-7.

53. Shah SP, Birur PN. Polarized light microscopic evaluation of remineralization by casein phosphopeptide-amorphous calcium phosphate paste of artificial caries-like lesion: An in vitro study. J Indian Acad Oral Med Radiol 2015;27:559-64.

54. Kardam P, Jain K, Mehendiratta M, Mathias Y. Kaleidoscope of oral artifacts: A vivid picture through light and polarizing microscope. Indian J Pathol Microbiol 2016;59:31-4

55. Heydarian H, Yazdanfar P, Zarif A, Rashidian B. Near field differential interference contrast microscopy. Sci Rep 2020;10:9644.

56. Obara B, Roberts MA, Armitage JP, Grau V. Bacterial cell identification in differential interference contrast microscopy images. BMC Bioinformat 2013;14:134.

57. Shribak M, Inoué S. Orientation-independent differential interference contrast microscopy. Appl Opt 2006;45:460-9.

58. Shribak M, LaFountain J, Biggs D, Inouè S. Orientation-independent differential interference contrast microscopy and its combination with an orientation-independent polarization system. J Biomed Opt 2008; 13:014011.

59. Fish KN. Total internal reflection fluorescence (TIRF) microscopy. Curr Protoc Cytom 2009; $12: 1218$

60. Guo M, Chandris P, Giannini JP, Trexler AJ, Fischer R, Chen J, et al. Single-shot super-resolution total internal reflection fluorescence microscopy. Nat Methods 2018;15;425-8.

61. Mattheyses AL, Simon SM, Rappoport JZ. Imaging with total internal reflection fluorescence microscopy for the cell biologist. J 
Cell Sci 2010;123:3621-8.

62. Schneckenburger H. Total internal reflection fluorescence microscopy: Technical innovations and novel applications. Curr Opin Biotechnol 2005;16:13-8.

63. Boulanger J, Gueudry C, Münch D, Cinquin B, Paul-Gilloteaux P, Bardin S, et al. Fast high-resolution 3D total internal reflection fluorescence microscopy by incidence angle scanning and azimuthal averaging. Proc Natl Acad Sci 2014;111:17164-9.

64. Larson A. Multiphoton microscopy. Nat Photon 2011;5:1.

65. Benninger RK, Piston DW. Two-photon excitation microscopy for the study of living cells and tissues. Curr Protoc Cell Biol 2013;4:59.

66. Diaspro A, Bianchini P, Vicidomini G, Faretta M, Ramoino P, Usai C. Multi-photon excitation microscopy. Biomed Eng Online 2006;5:36.

67. Ingaramo M, York AG, Wawrzusin P, Milberg O, Hong A, Weigert R, et al. Two-photon excitation improves multifocal structured illumination microscopy in thick scattering tissue. Proc Natl Acad Sci 2014;111:5254-9.

68. Zhanghao K, Chen X, Liu W, Wang Y, Luo S, Wang X, et al. Superresolution imaging of fluorescent dipoles via polarized structured illumination microscopy. Nat Commun 2019;10:4694.

69. Markwirth A, Lachetta M, Mönkemöller V, Heintzmann R, Hübner W, Huser T, et al. Video-rate multi-color structured illumination microscopy with simultaneous real-time reconstruction. Nat Commun 2019;10:4315.

70. Curd A, Cleasby A, Makowska K, York A, Shroff H, Peckham M. Construction of an instant structured illumination microscope. Methods 2015;88:37-47.

71. Yadav A, Rao C, Nandi CK. Fluorescent probes for super-resolution microscopy of lysosomes. ACS Omega 2020:5:26967-77.

72. Ryl PS, Bohlke-Schneider M, Lenz S, Fischer L, Budzinski L, Stuiver M, et al. In situ structural restraints from cross-linking mass spectrometry in human mitochondria. J Prot Res 2020;19:327-36.

73. Fang H, Yao S, Chen Q, Liu C, Cai Y, Geng S, et al. De novo-designed near-infrared nanoaggregates for super-resolution monitoring of lysosomes in cells, in whole organoids, and in vivo. ACS Nano 2019:13:14426-36.

74. Mako TL, Racicot JM, Levine M. Supramolecular luminescent sensors. Chem Rev 2019;119:322-477.

75. Wijesooriya CS, Nyamekye CK, Smith EA. Optical imaging of the nanoscale structure and dynamics of biological membranes. Anal Chem 2019;91:425-40.

76. Hui F, Lanza M. Scanning probe microscopy for advanced nanoelectronics. Nat Electron 2019;2:221-9.

77. Colton RJ, Baselt DR, Dufrêne YF, Green JB, Lee GU. Scanning probe microscopy. Curr Opin Chem Biol 1997;1:370-7.

78. Ushiki T. SS2-1Scanning probe microscopy and its biomedical application from the historical viewpoint. Microscopy 2019;68:i27.

79. Krieg M, Fläschner G, Alsteens D, Gaub BM, Roos WH, Wuite GJ, et al. Atomic force microscopy-based mechanobiology. Nat Rev Phys 2019;1:41-57.

80. Jalili N, Laxminarayana K. A review of atomic force microscopy imaging systems: Application to molecular metrology and biological sciences. Mechatronics 2004;14:907-45.

81. Dufrêne YF. Atomic force microscopy, a powerful tool in microbiology. J Bacteriol 2002;184:5205-13.

82. Marti O, Elings V, Haugan M, Bracker CE, Schneir J, Drake B, et al. Scanning probe microscopy of biological samples and other surfaces. J Microsc 1988;152:803-9.

83. Hirano Y, Takahashi H, Kumeta M, Hizume K, Hirai Y, Otsuka S, et al. Nuclear architecture and chromatin dynamics revealed by atomic force microscopy in combination with biochemistry and cell biology. Pflugers Arch 2008;456:139-53.

84. Kuznetsov YG, Victoria JG, Robinson WE Jr, McPherson A. Atomic force microscopy investigation of human immunodeficiency virus (HIV) and HIV-infected lymphocytes. J Virol 2003;77:11896-909.

85. Arif M, Kumar GV, Narayana C, Kundu TK. Autoacetylation induced specific structural changes in histone acetyltransferase domain of p300: Probed by surface enhanced Raman spectroscopy. J Phys Chem B 2007;111:11877-9.

86. Morikawa K, Ohniwa RL, Kim J, Maruyama A, Ohta T, Takeyasu K. Bacterial nucleoid dynamics: Oxidative stress response in Staphylococcus aureus. Genes Cells 2006;11:409.

87. Stylianou A, Kontomaris SV, Grant C, Alexandratou E. Atomic force microscopy on biological materials related to pathological conditions. Scanning 2019;2019:8452851.

88. Golding C, Lamboo L, Beniac D, Booth TF. The scanning electron microscope in microbiology and diagnosis of infectious disease. Sci
Rep 2016;6:26516.

89. Thiberge S, Nechushtan A, Sprinzak D, Gileadi O, Behar V, Zik O, et al. Scanning electron microscopy of cells and tissues under fully hydrated conditions. Proc Natl Acad Sci 2004;101:3346-51.

90. Philips Corporation. Environmental Scanning Electron Microscope. El Dorado Hills, CA: Robert Johnson Assoc; 1996.

91. Goldstein JI, Newbury DE, Echlin P, Joy DC, Romig AD, Lyman CE, et al. Scanning Electron Microscopy and X-Ray Microanalysis. $2^{\text {nd }}$ ed. New York: Plenum; 1992.

92. Boyde A, Reid SA. A new method of scanning electron microscopy for imaging biological tissues. Nature 1983;302:522-3.

93. Joy D, Ko YU, Hwu J. Proceeding SPIE 3998; 2000. p. 108-115. available from: http://www.web.utk.edusrcutk.

94. Levenberg S, Katz BZ, Yamada KM, Geiger B. Longrange and selective autoregulation of cell-cell or cell-matrix adhesions by cadherin or integrin ligands. J Cell Sci 1998;111:347-57.

95. Chowers MY, Keller N, Tal R, Barshack I, Lang R, Bar-Meir S, Chowers Y. Human gastrin: A Helicobacter pylori specific growth factor. Gastroenterology 1999;117:1113-8.

96. Liu L, Liang XH, Uliel S, Unger R, Ullu E, Michaeli S. RNA interference of signal peptide-binding protein SRP54 elicits deleterious effects and protein sorting defects in trypanosomes. J Biol Chem 2002;277:47348-67.

97. Ning G, Fugimoto T, Koike H, Ogawa K. Cathodoluminescenceemitting lipid droplets in rat testis: a study by analytical color fluorescence electron microscopy. Cell Tissue Res 1993;271:217-25.

98. Brown DA. Lipid droplets: proteins floating on a pool of fat. Curr Biol 2001;11:R446-9.

99. Bosworth N, Towers P. Scintillation proximity assay. Nature 1989;341;167-68.

100. National Research Council. Health Effects of Exposure to Low Levels of Ionizing Radiation, Biological Effects of Ionizing Radiation Report 5. Washington, DC: The National Academies Press; 1990.

101. Dos Santos QM, Dzika E, Avenant-Oldewage A. Using scanning electron microscopy (SEM) to study morphology and morphometry of the isolated haptoral sclerites of three distinct diplozoid species. PLoS One 2019;14:e211794.

102. Smith KC, Oatley CW. The scanning electron microscope and its fields of application. Br J Appl Phys 1955;6:391.

103. Dai B, Jiao Z, Zheng L, Bachman H, Fu Y, Wan X, et al. Colour compound lenses for a portable fluorescence microscope. Light Sci Appl 2019;8:75.

104. Toda K, Tamamitsu M, Nagashima Y, Horisaki R, Ideguchi T. Molecular contrast on phase-contrast microscope. Sci Rep 2019;9:9957.

105. Park Y, Christian D, Gabriel P. Quantitative phase imaging in biomedicine. Nat Photon 2018;12;578-89.

106. Yin Z, Kanade T, Chen M. Understanding the phase contrast optics to restore artifact-free microscopy images for segmentation. Med Image Anal 2012;16:1047-62.

107. Palima D, Glückstad J. Generalised phase contrast: Microscopy, manipulation and more. Contemp Phys 2010;51:249-65.

108. Ueno H, Nishikawa S, Iino R, Tabata KV, Sakakihara S, Yanagida T, et al. Simple dark-field microscopy with nanometer spatial precision and microsecond temporal resolution. Biophys J 2010;98:2014-23.

109. Kim JH, Park JS. Partial dark-field microscopy for investigating domain structures of double-layer microsphere film. Sci Rep 2015;5:10157.

110. Zhang J Li Y, Zhang X, Yang B. Colloidal self-assembly meets nanofabrication: From two-dimensional colloidal crystals to nanostructure arrays. Adv Mater 2010;22:4249-69.

111. Antolović V, Marinović M, Filić V, Weber I. A simple optical configuration for cell tracking by dark-field microscopy. J Microbiol Methods 2014;104:9-11.

112. Mehta V, Saurav K, Balachandran C. Dark ground microscopy. Indian J Sex Transm Dis 2008;29:105-6.

113. Abdel-Fattah AI, El-Genk MS, Reimus PW. On visualization of submicron particles with dark-field light microscopy. J Colloid Interface Sci 2002;246:410-2.

114. Lee CW, Chen MJ, Cheng JY, Wei PK. Morphological studies of living cells using gold nanoparticles and dark-field optical section microscopy. J Biomed Opt 2009;14:034016.

115. Magidson V, Khodjakov A. Circumventing photodamage in livecell microscopy. In: Sluder G, Wolf DE, editors. Digital microscopy. In: Book Series: Methods in Cell Biology. Vol. 114. Amsterdam, Netherlands: Elsevier Inc.; 2013. p. 545-60.

116. Nenasheva TA, Carter T, Mashanov GI. Automatic tracking of 
individual migrating cells using low-magnification dark-field microscopy. J Microsc 2012;246:83-8.

117. Sanderson MJ, Smith I, Parker I, Bootman MD. Fluorescence microscopy. Cold Spring Harb Protoc 2014;2014:pdb.top071795.

118. Combs CA. Fluorescence microscopy: A concise guide to current imaging methods. Curr Protoc Neurosci 2010;2:2.

119. Lichtman J, Conchello JA. Fluorescence microscopy. Nat Methods 2005;2:910-9.

120. Adams JK, Boominathan V, Avants BW, Vercosa DG, Ye F, Baraniuk RG, et al. Single-frame 3D fluorescence microscopy with ultraminiature lensless flat scope. Sci Adv 2017;3:e1701548.

121. Kanemaru T, Hirata K, Takasu S, Isobe S, Mizuki K, Mataka S, et al. A fluorescence scanning electron microscope. Mater Today 2010;12:18-23.

122. Hasan MM, Alam MW, Wahid KA, Miah S, Lukong KE. A low-cost digital microscope with real-time fluorescent imaging capability. PLoS One 2016;11:e0167863.

123. Ilie MA, Caruntu C, Lupu M, Lixandru D, Tampa M, Georgescu SR, et al. Current and future applications of confocal laser scanning microscopy imaging in skin oncology. Oncol Lett 2019;17:4102-11.

124. Nwaneshiudu A, Kuschal C, Sakamoto FH, Anderson RR, Schwarzenberger K, Young RC. Introduction to confocal microscopy. J Investig Dermatol 2012;132:1-5.

125. Elliott AD. Confocal microscopy: Principles and modern practices Curr Protoc Cytometry 2019;92:68.

126. Jonkman J, Brown CM, Wright GD, Anderson KI, North AJ Tutorial: Guidance for quantitative confocal microscopy. Nat Protoc 2020;15:1585-611.

127. Paddock SW. Principles and practices of laser scanning confocal microscopy. Mol Biotechnol 2000;16:127-49.
128. Goldsmith CS, Miller SE. Modern uses of electron microscopy for detection of viruses. Clin Microbiol Rev 2009;22:552-63.

129. Doane FW, Anderson N. Electron Microscopy in Diagnostic Virology: A Practical Guide and Atlas. New York: Cambridge University Press; 1987.

130. Williams DB, Carter CB. The transmission electron microscope. In: Transmission Electron Microscopy. Boston, MA: Springer; 1996.

131. Tang CY, Yang Z. Transmission electron microscopy (TEM). In Membrane Characterization. Amsterdam, Netherlands: Elsevier; 2017. p. 145-59.

132. Winey M, Meehl JB, O'Toole ET, Giddings TH Jr. Conventional transmission electron microscopy. Mol Biol Cell 2014;25:319-23.

133. Casciardi S, Sisto R, Diociaiuti M. The analytical transmission electron microscopy: A powerful tool for the investigation of lowdimensional carbon nanomaterials. J Nanomater 2013;2013:506815.

134. Beniac DR, Siemens CG, Wright CJ, Booth TF. A filtration base technique for simultaneous SEM and TEM sample preparation for the rapid detection of pathogens. Viruses 2014;6:3458-71

135. Thiberge S, Nechushtan A, Sprinzak D, Gileadi O, Behar V, Zik O, et al. Scanning electron microscopy of cells and tissues under fully hydrated conditions. Proc Natl Acad Sci USA 2004;101:3346-51

136. Walther P, Muller M. Biological ultrastructure as revealed by high resolution cryo-SEM of block faces after cryo-sectioning. J Microsc 1999; 196:279-87.

137. Thomas JM. Reflections on the value of electron microscopy in the study of heterogeneous catalysts. Proc R Soc A 2017;473:20160714.

138. Liu J, Cowley JM. Scanning reflection electron microscopy and associated techniques for surface studies. Ultramicroscopy 1993;48:381-416.

139. Yagi K. Reflection electron microscopy. J Appl Crystallogr 1987;20:147-60. 